\title{
Large-Scale Physical Mapping within the Region 22q12.3-13.1 in Meningioma
}

\author{
Ruth Herzog, * Elisabeth Gottert, * Wolfram Henn, * Klaus Zang, * \\ Nikolaus Blin, * JefFrey Trent, † and ECKart Meese† ${ }^{* 1}$ \\ "University of Saarland, Department of Human Genetics, Homburg/Saar, Germany; and HUniversity of Michigan Medical Center, \\ Department of Radiation Oncology, Division of Cancer Biology, Ann Arbor, Michigan, 48109
}

Received January 16, 1991; revised April 18, 1991

The lack of physical mapping data strongly restricts the analysis of the meningioma chromosomal region that was assigned to the bands 22q12.3-qter. Recently, we reported a new marker D22S16 for chromosome 22 that was assigned to the region 22q13-qter by in situ hybridization. Utilizing somatic cell hybrids we now sublocalized the marker D22S16 within the band region 22q12-13.1, thus placing it in the vicinity of the gene for the platelet derived growth factor (PDGFB). A physical map was established for the regions surrounding the PDGFB gene and the D22S16 marker. By means of pulsed-field gel electrophoresis (PFGE) D22S16 and PDGFB were found to be physically linked within $900 \mathrm{~kb}$. We also identified two CpG clusters bordering the PDGFB gene. For the enzyme NotI, a variation of the PDGFB restriction pattern was found between different individuals. PFGE analysis of the two loci (PDFGB and D22S16) failed to identify major rearrangements in meningioma. (c) 1981 Academic Press, Inc.

\section{INTRODUCTION}

Chromosome 22 contains only $1.9 \%$ of the total haploid human genome $\sim 57,000 \mathrm{~kb}$ (Rouleau et al., 1989). Despite its small size, chromosome 22 is involved in numerous inherited and acquired diseases (for review, see Kaplan et al., 1987). Accordingly, a physical map of chromosome 22 will contribute to the analysis of disorder-related rearrangements (e.g., in meningioma). By means of restriction fragment length polymorphisms (RFLPs), genetic mapping has provided the gene location for hereditary disorders such as Huntington's disease and cystic fibrosis (Gusella et al., 1983; White et al., 1985). However, genetic mapping requires polymorphic probes and informative disease pedigrees.

\footnotetext{
1 To whom reprint requests should be addressed at University of Michigan Medical Center, Department of Radiation Oncology, Division of Cancer Biology, Ann Arbor, Michigan 48109.
}

For meningiomas only a few kindreds have been described and map resolution is limited by availability of useful RFLP probes. Even until most recently, available RFLP probes have been only adequate to assign the candidate recessive oncogene to a relatively large 20-cM region between 22q12.3 and qter (Dumanski et al., 1987; Meese et al., 1987; Dumanski et al., 1990).

The technique of pulsed-field gel electrophoresis (PFGE) (Carle and Olson, 1984; Schwartz and Cantor, 1984) offers a powerful approach to generate precise mapping information that does not depend upon recombination frequency. This is especially important for chromosome 22 where the genetic map (97 cM) exceeds the calculated physical length $(60 \mathrm{cM})$ by more than $60 \%$, indicating a high recombination frequency (Rouleau et al., 1989). Using PFGE, only a limited number of probes (e.g., 100 adjacent fragments of $500 \mathrm{~kb}$ ) would be required for establishing a long-range restriction map spanning the entire chromosome 22.

As a starting point for the physical map within the meningioma chromosomal region we chose the protooncogene PDGFB (22q12.3-13.1), which is the most proximal marker to be lost in meningioma with a $(46,22 q-)$ karyotype (Dumanski et al., 1987, 1990). Using a panel of somatic cell hybrids the marker D22S16 was localized to the same band region. Longrange restriction mapping is reported for both sequences (D22S16 and PDGFB), placing both loci on a restriction fragment of $900 \mathrm{~kb}$. Utilizing this mapping information we have studied possible rearrangements of PDGFB and D22S16 in meningioma.

\section{MATERIALS AND METHODS}

\section{Cell Culture}

Meningioma tumor specimens and skin biopsies from the same patients were obtained freshly after 

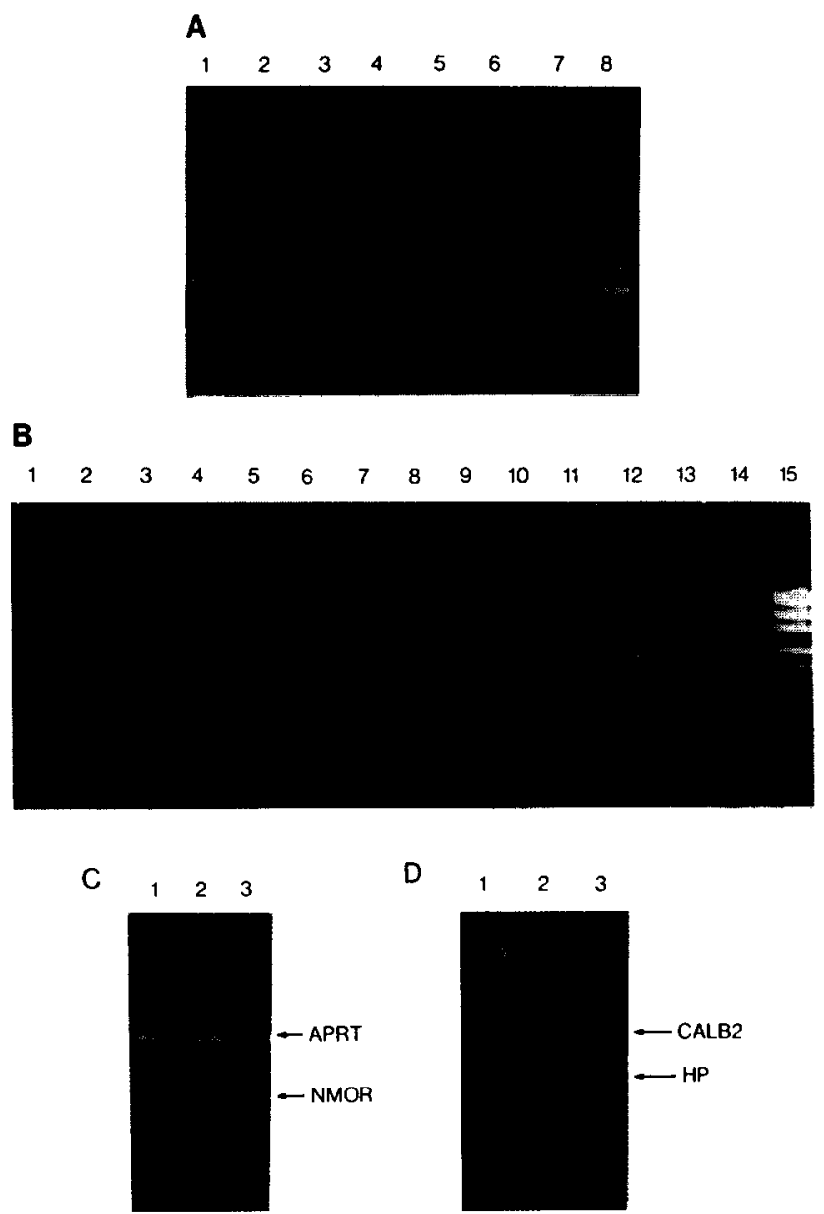

FIG. 1. (A) Multiplex reaction 1 with somatic cell hybrid DNAs as templates. Lane 1, CY14; 2, CY7; 3, CY125; 4, CY4; 5, CY2; 6, CY3; 7, A9 (mouse parent cell line used to generate most of the somatic cell hybrids); 8 , human blood bank DNA. A mousederived PCR product is present in some reactions (lanes 1,5 , and 7); however, it can be readily distinguished from the STS PCR products and therefore does not interfere with the deletion analysis. The composition and sizes of multiplex 1 PCR products are given in Table 1. (B) Multiplex reactions 2 (lanes 1 to 7 ) and 3 (lanes 8 to 14) with somatic cell hybrid DNAs as templates. Lanes 1 and 8, human blood bank DNA; lane 2, CY14; lane 3, CY15; lanes 4 and 10, CY8; lanes 5 and 12, CY2; lanes 6 and 13, CY3; lanes 7 and 14, mouse A9 cell line; lane 9, CY12; lane 11, CY4; lane 15, HpaII-cut pUC19. The composition and sizes of multiplex 2 and 3 PCR products are given in Table 1. Artifactual PCR products of unknown origin are present in multipex $2(\sim 140 \mathrm{bp})$ in lanes 1-5 and primer dimer products are present in all reactions including mouse DNA controls. None of these bands interferes with the assignment of any locus. (C) Mapping NMORI using APRT (403) PCR product as positive control. Lane 1, CY18; lane 2, CY6; lane 3, CY5. (D) Mapping CALB2 using HP PCR product as positive control. Lane 1, CY18; lane 2, CY5; lane 3, CY170.

and Table 2). PCR products were electrophoresed in $1.4 \%$ agarose gels and stained with ethidium bromide.

Each of the multiplex reactions was optimized for $\mathrm{Mg}^{2+}$ concentration over the range of 3 to $9 \mathrm{mM}$ $\mathrm{MgCl}_{2}$ at $1.5 \mathrm{~m} M$ intervals (data not shown). The relatively high optimum $\mathrm{Mg}^{2+}$ concentrations for these reactions are due to the high nucleotide concentrations used (Kogan et al., 1987) which favor multiplexing (Chamberlain et al., 1988).

The somatic cell hybrid panel was derived using alanosine and adenine selection for $\mathrm{APRT}^{+}$phenotype on an aprt ${ }^{-}$A9 mouse cell line background (Callen, 1986). The human chromosomes were derived from cell lines containing various translocations or deletions of chromosome 16. The human APRT gene maps to the distal tip of the long arm of chromosome 16 and all but one of the hybrids tested contain this locus. These hybrids therefore have breakpoints that map either on the short arm or proximal to the APRT locus on the long arm. The one hybrid that does not contain APRT is CY3, which was constructed by selection of the HPRT gene present on the X chromosome, as the chromosome $\mathbf{1 6}$ material in this hybrid originated from an X;16 translocation (Callen, 1986). The PCR marker for the APRT gene was used as an internal positive control to verify negative results from the analysis of other loci. Two APRT PCR markers were designed utilizing the same forward primer but different reverse primers, and generated a 200- or 403-bp PCR product (Table 1). This allowed for greater flexibility in the design of multiplex reactions (Table 2). Additional STSs were chosen from available DNA sequences of genes known to map to chromosome 16 and, where possible, from evenly spaced intervals over the length of the chromosome. In those cases where only cDNA sequence was available, primer sequences were synthesized from the $3^{\prime}$ untranslated region in an attempt to avoid spanning introns.

In all but one instance the size of the PCR product matched the published nucleotide sequence. The $C R 3 A$ product was predicted to be 569 bp but was found to give a 490 -bp product. This gene mapped to the $16 \mathrm{p} 11-\mathrm{q} 11$ region, which is consistent with its previous localization (Corbi et al., 1988). The sequence between the two PCR primers at this locus contains about $200 \mathrm{bp}$ which comprise mainly GT dinucleotide repeats. Such repeats are frequently polymorphic (Weber and May, 1989) and this may ac-

TABLE 2

\begin{tabular}{lcc}
\hline & Multiplex & \\
\hline 1 (locus) & 2 (locus) & 3 (locus) \\
\hline & PCR product (bp) & \\
$403(A P R T)$ & $403(A P R T)$ & $490(C R 3 A)$ \\
$354(P K C B)$ & $314(S P N)$ & $354(P K C B)$ \\
$290(M T)$ & $270(P R M 1)$ & $290(M T)$ \\
$237(H P)$ & $237(H P)$ & $200(A P R T)$ \\
$180(L C A T)$ & $174(H B A)$ & $180(L C A T)$ \\
\hline
\end{tabular}



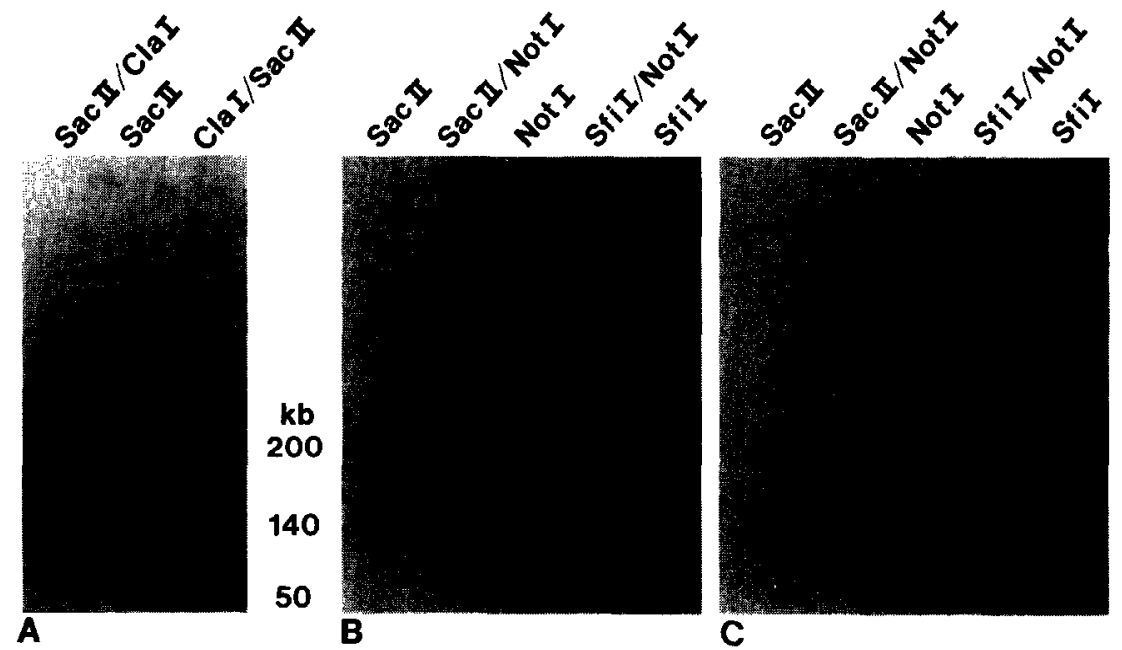

C

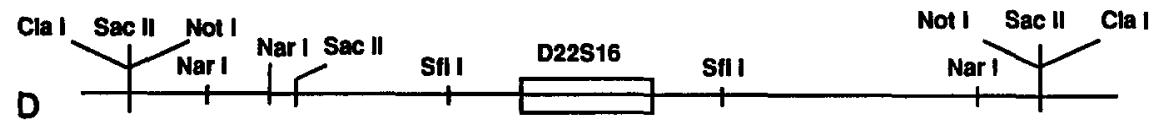

FIG. 2. (A, B) PFGE analysis of the marker D22S16 by double digest. Lymphocyte DNA was digested as indicated, separated by PFGE and probed with D22S16. The running conditions are given under Materials and Methods. (C) PFGE analysis of the gene PDGFB by double digest. The blot shown in Fig. 4B was hybridized with PDGFB. The hybridization with PDGFB yields fragments of similar size (as opposed to the size distribution obtained after hybridization with D22S16). (D) Large-scale map of the region flanking the sequence D22S16. The map is derived from the results summarized in Table 1.

and $2 \mathrm{~B})$. Given the fact that the restriction sites for ClaI, NotI, and SacII are clustered and that the ClaI sites are situated outside the $S f I$ I sites, the NotI sites and the SacII sites should also fall outside the $S f i \mathrm{I}$ fragment. This extrapolation was verified by a $S f i \mathrm{I} /$ NotI and a Sfi I/SacII double digest leaving the size of the $S f i$ I fragment unaltered (Fig. 2B). Next to the SacII band at $200 \mathrm{~kb}$ an additional SacII band at 140 kb was found. The SacII pattern remains unaltered even by an extended digestion with increased amounts of restriction enzyme, suggesting hypermethylation of SacII sites. The smaller SacII fragment at $140 \mathrm{~kb}$ remains unaltered by subsequent digestion with NotI or ClaI, indicating a SacII site within the 200 -kb fragment that is flanked by the SacII/ClaI/NotI cluster. The size of the NarI fragments appears to be unchanged by subsequent restriction with $S f I$, placing the restriction sites for NarI between the $S f I I$ fragment and the ClaI/NotI/SacII cluster. These results are summarized in the map shown in Fig. 2D.

\section{Large-Scale Restriction Mapping for PDGFB}

To map the PDGFB region we used the same rare cutting endonucleases as for the physical mapping of D22S16. In most cases, we obtained restriction fragments in the size range between 110 and $130 \mathrm{~kb}$, sug- gestive of two clusters of $\mathrm{CpG}$ islands (Fig. 3). These findings are in good agreement with the localization of HTF islands (HpaII tiny fragments) upstream from the PDGFB gene (Gardiner-Garden and From-

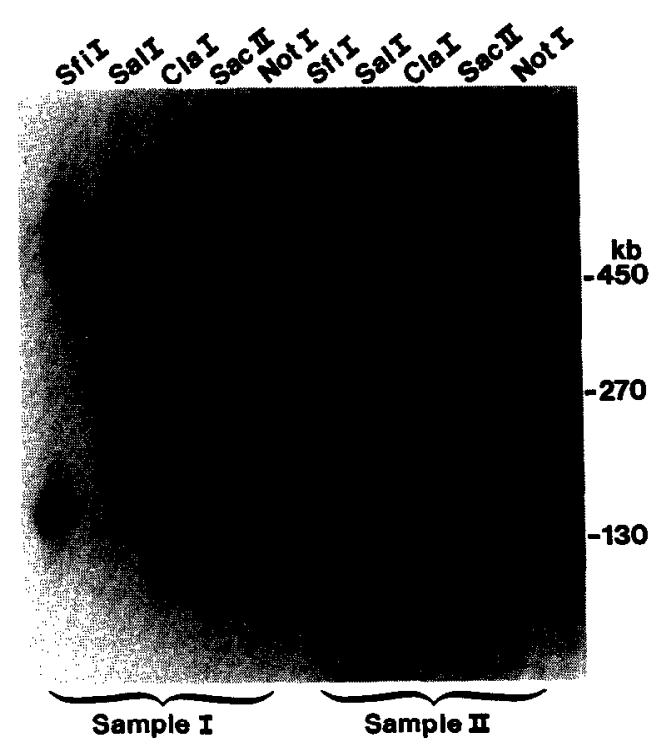

FIG. 3. PFGE analysis of the gene PDGFB by single digest. DNA from two different lymphocyte samples was cleaved as indicated, separated by PFGE, and hybridized with PDGFB. The running conditions are given under Materials and Methods. 


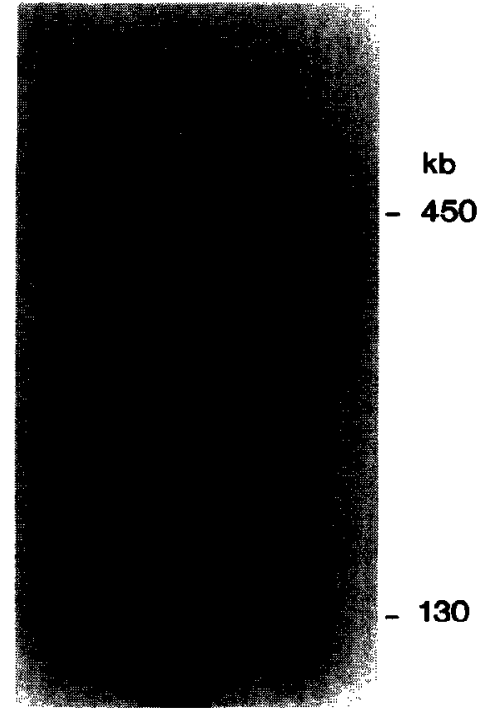

FIG. 4. Variations of the NotI restriction pattern identified by PFGE. Lymphocyte DNA from three individuals was digested with NotI, separated by PFGE, and hybridized with PDGFB. The running conditions are given under Materials and Methods. Next to the 130 -kb band an additional signal at $450 \mathrm{~kb}$ can be demonstrated in two lymphocyte samples.

mer, 1987). HTF islands contain a high frequency of unmethylated $\mathrm{CpG}$ dinucleotides and, therefore, a higher density of restriction sites for rare cutting enzymes. These results were confirmed by a combination of double digests: The fragment sizes obtained in a single restriction are not significantly reduced by subsequent restriction with a second enzyme, placing the recognition sites for the used enzymes close to each other (Fig. 2C).

To ensure that both enzymes were active in the double digest each experiment was accompanied by two single digests using the enzymes separately. In addition, all blots were hybridized with both probes. A representative blot is shown in Figs. 2B and 2C. Following hybridization with PDGFB the probe was removed, and the blot was rehybridized with the D22S16 probe. As demonstrated in Fig. 2C, PDGFB fragments of similar size have been found in the single NotI and SfiI digests and in the NotI/SfiI double digests. Following rehybridization with D22S16, the size of the NotI fragment $(200 \mathrm{~kb})$ was reduced to 50 $\mathrm{kb}$ in a NotI/SfiI double digest. A band of $50 \mathrm{~kb}$ was also found following the single $S f i \mathrm{I}$ digest (Fig. 4B).

Finally, a variation of the NotI restriction pattern has been found between different individuals. As demonstrated in Fig. 4, next to the 130-kb band, we found an additional $450-\mathrm{kb}$ signal in some lymphocyte samples. While the $130-\mathrm{kb}$ band was observed in all individuals, the additional band was only found in 7 of 11 individuals. In none of the tested samples did we detect a single $450-\mathrm{kb}$ band.

Variation of the NotI restriction pattern has already been described for other probes such as pmetH in which case the variation is due to a site polymorphism (Julier and White, 1988; Collins et al., 1987). It remains to be shown whether the PDGFB variation reflects a point mutation, a major rearrangement, or a difference in the methylation pattern.

\section{Physical Linkage of PDGFB and D22S16}

To physically link the gene PDGFB and the marker D22S16, we used extended pulsed times and conditions for partial restriction digestion (Fig. 5). Restriction fragments containing the two loci were identified by sequential hybridization to both probes. The restriction endonucleases $N o t \mathrm{I}, S f i \mathrm{I}$, and $\mathrm{ClaI}$ did not produce DNA fragments long enough to be recognized by the two probes. However, the enzyme NruI revealed two fragments ( 900 and $1300 \mathrm{~kb}$ ) that hybridize to D22S16 and PDGFB, thereby, indicating the maximum distance for these two markers (Fig. 5). Linkage was also found using the enzyme MluI, confirming the results obtained by $\mathrm{NruI}$ digest. Smaller $\mathrm{NruI}$ fragments that were unique to each probe in-
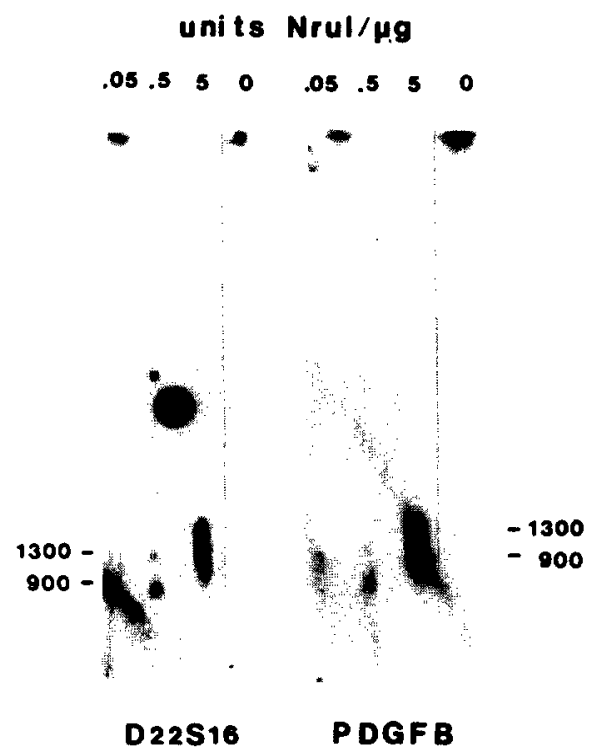

FIG. 5. Physical linkage of the marker D22S16 and the gene PDGFB. The DNA was restricted by increasing concentrations of $N r u I$ and separated by PFGE. The running conditions were as follows: The pulse time was gradually increased from 30 to $60 \mathrm{~min}$ for $144 \mathrm{~h}$, followed by a second ramp from 10 to $30 \mathrm{~min}$ for $22 \mathrm{~h}$. Following transfer, the membrane was hybridized to PDGFB, the probe was removed, and the blot was reprobed with D22S16. The two bands (900 and $1300 \mathrm{~kb}$ ) migrated a slightly reduced distance when more fragments were generated by increasing enzyme concentrations. 
A
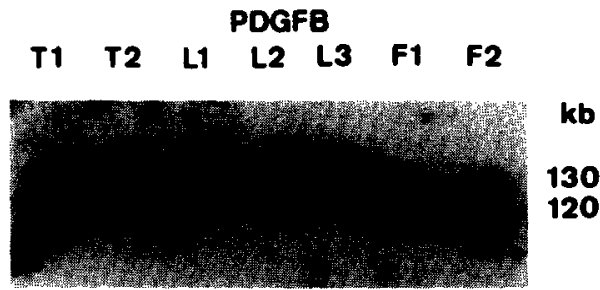

B

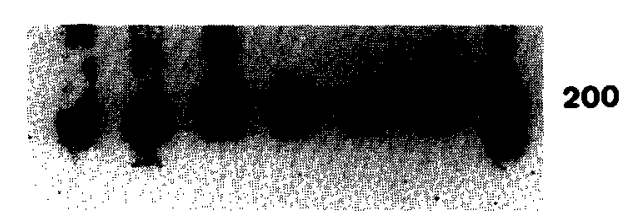

FIG. 6. PFGE analysis of meningioma DNA using D22S16 and PDGFB. (A) The indicated samples (T1, T2-meningioma DNA; L1, L2, L3-lymphocyte DNA; F1, F2-fibroblast DNA) were digested by NotI, separated by PFGE, and probed with PDGFB. The running conditions are given under Materials and Methods. (B) Following hybridization with PDGFB, the blot shown in A was stripped and rehybridized with D22S16.

clude a 400-kb fragment for D22S16 and a fragment at $500 \mathrm{~kb}$ for PDGFB (data not shown).

\section{PFGE Analysis of Meningiomas}

The flanking regions of PDGFB and D22S16 have been analyzed in cell cultures from six meningiomas. Following restriction with NotI, PDGFB fragments of identical sizes have been identified in meningioma and fibroblasts (Fig. 6), as well as in dura mater and arachnoid DNA (data not shown). Arachnoid cells are considered to be the cells of origin for meningioma. Lymphocyte DNA reveals a slightly different methylation status. Following hybridization with D22S16, an identical pattern was demonstrated in all analyzed cell types. Two additional enzymes ( $\mathrm{ClaI}$ and SacII) also failed to demonstrate specific alterations in meningiomas.

\section{DISCUSSION}

The migration of DNA molecules in PFGE gels depends on a number of variables (e.g., switching time, voltage gradient, DNA concentration, etc.) and can easily be modified by even small variations of one of the parameters (Birren et al., 1988). For example, the occurrence of a peak in the size distribution of restriction fragments may result in altered migration due to local overloading of the gel. Therefore, we included several controls for each experiment. First, all experiments were repeated three times with DNA from different individuals. Second, as mentioned above, in cases where the fragment size remained unaltered by subsequent digest with another enzyme, we rehybridized with a second unrelated probe. Finally, the order of the restriction enzymes used in the double digest was reversed (e.g., the results of a ClaI/SacII digest were verified by a SacII/ClaI restriction).

As a starting point for the large scale restriction map of chromosome 22, we have chosen the proto-oncogene PDGFB. Surprisingly, relatively small fragments have been identified even for enzymes (e.g., NotI that usually generate significantly larger fragments (Barlow and Lehrach, 1987)). Using a combination of single and double digests we identified two CpG clusters flanking the PDGFB gene. Using the GeneBank sequence data, Gardiner-Garden and Frommer (1987) analyzed the distribution of HTF islands with respect to gene termini. They identified $\mathrm{CpG}$ islands predominantly at the $5^{\prime}$ end of many analyzed genes including PDGFB. In a few instances both $5^{\prime}$ and $3^{\prime} \mathrm{CpG}$ islands were found. Our results support the notion that an HTF island is present $3^{\prime}$ to the PDGFB gene. However, the possibility cannot yet be excluded that this HTF island may represent a $5^{\prime}$ $\mathrm{CpG}$ cluster related to an as yet unidentified transcription unit bordering the $3^{\prime}$ end of the PDGFB gene.

We report here the extension of the physical map surrounding the PDGFB gene. The marker D22S16 was sublocalized to the band region 22q13.1 utilizing a hybrid mapping panel. By means of PFGE D22S16 was shown to be situated within $900 \mathrm{~kb}$ of the PDGFB gene. In addition, we studied meningiomas using these two probes in PFGE experiments. Neither PDGFB nor D22S16 detected any structural rearrangement in meningioma.

Our results should assist in localizing the region of the putative suppressor gene in meningioma. Together with the recently published physical map of the band region 22q11 (McDermid et al., 1989), our data for the region 22q12.3-13.1 contribute to the development of a complete physical map of chromosome 22 .

\section{ACKNOWLEDGMENTS}

The work was supported in part by a grant to N.B. (DFG B1 166/3). R.H. was a recipient of a predoctoral fellowship of the University of Saarland. This research was supported in part by CA41183 (J.M.T., E.M.). We also acknowledge the technical assistance of Mrs. Sharon Olson, Silvia Bernhard, and Monika Thonnes.

\section{REFERENCES}

1. Barlow, D. P., AND LeHrach, H. (1987). Genetics by gel electrophoresis: The impact of pulsed field gel electrophoresis on mammalian genetics. Trends Genet. 3: 167-171. 
2. Birren, B. W., Lai, E., Clark, S. M., Hood, L., AND Simon, M. I. (1988). Optimized conditions for pulsed field gel electrophoretic separations of DNA. Nucleic Acids Res. 16: 75637582.

3. Carle, G. F., AND Olson, M. V. (1984). Separation of chromosomal DNA molecules from yeast by orthogonal-field-alteration gel electrophoresis. Nucleic Acids Res. 12: 56475664.

4. Collins, F. S., Drumm, M. L., Cole, J. L., Lockwood, W. K., VAN DE Woude, G., AND IANNuzI, M. C. (1987). Construction of a general human chromosome jumping library with application to cystic fibrosis. Science 235: 1046-1049.

5. Dumanski, J. P., Carlbom, E., Collings, V. P., and NorDENSKJOLD, M. (1987). Chromosome 22q deletions in meningiomas detected by RFLP analysis: Human Gene Mapping 9. Cytogenet. Cell Genet. 46: 608-609.

6. Dumanski, J. P., Rouleau, G. A., NordenskJold, M., AND Collins, P. (1990). Molecular genetic analysis of chromosome 22 in 81 cases of meningioma. Cancer Res. 50: 58635867.

7. Feinberg, A., AND Vogelstein, B. (1984). A technique for labeling DNA restriction fragments to a high specific activity. Anal Biochem. 137: 66-67.

8. Gardiner-Garden, M., and Frommer, M. (1987). CpG islands in vertebrate genomes. J. Mol. Biol. 196: 261-282.

9. Geurts van Kessel, A. H. M., Turc-Carel, C., DeKlein, A., Grosveld, G., LenoIr, G., Bootsma, D. (1985). Translocation of oncogene $c$-sis from chromosome 22 to chromosome 11 in an Ewing sarcoma-derived cell line. Mol. Cell. Biol. 5: 427-429.

10. Geurts van Kessel, A. H. M., Westerveld, A., De Groot, P. G., Meera Khan, P., AND Hagemeijer, A. (1980). Regional localization of the genes coding for human ACO2, ARSA, and NAGA on chromosome 22. Cytogenet. Cell Genet. 28: 169-172.

11. GotTert, E., Metzdorf, R., Farber, U., AND Blin, N. (1989). Regional localization and molecular characterization of DNA sequence on the long arm of chromosome 22. Hum. Genet. 81: 385-387.

12. Groffen, J., Heisterkamp, N., Stephenson, J. R., Geurts van Kessel, A., DeKlein, A., Grosveld, G., AND Bootsma, D. (1983). C-sis is translocated from chromosome 22 to chromosome 9 in chronic myeloid leukemia. J. Exp. Med. 158: 9-15.
13. Gusella, J. F., Wexler, N. S., Conneally, P. M., Naylor, S. L., Anderson, M. A., Tanzi, R. E., Watkins, P. C., OTtina, K., Wallace, M. R., Sakuchi, A. Y., Young, A. B., Shoulson, I., Bonilla, E., AND MarTin, J. B. (1983). A polymorphic DNA marker genetically linked to Huntington's disease. Nature 306: 234-238.

14. JULIER, C., AND WHITE, R. (1988). Detection of NotI polymorphism with the pmetH probe by pulsed field gel electrophoresis. Am. J. Hum. Genet. 42: 45-48.

15. Kaplan, J. C., Aurias, A., Julier, C., Prieur, M., and SzajNERT, M.-F. (1987). Human chromosome 22. J. Med. Genet. 24: $65-78$.

16. Limon, J., Dal Cin, P., AND SandBerg, A. A. (1986). Application of long-term collagenase disaggregation for the cytogenetic analysis of human solid tumors. Cancer Genet. Cytogenet. 23: 305-313.

17. MCDermid, H. E., BUdARF, M. L., AND EMaUEL, B. S. (1989). Toward a long-range map of human chromosomal band 22q11. Genomics 5: 1-8.

18. MEESE, E., BLIN, N., AND ZANG, K. D. (1987). Loss of heterozygosity and the origin of meningioma. Hum. Genet. 77: 349351.

19. Meese, E., AND Meltzer, P. S. (1990). A modified CHEF system for PFGE analysis. Technique 2: 36-42.

20. Meese, E., Meltzer, P. S., AND Trent, J. M. (1989). Application of natural partial digests to pulsed field gel analysis of the amplified mdr locus. Genomics 5: 371-374.

21. Mullenbach, R., Lagoda, P. J. L., AND Welter, C. (1989). An efficient salt-chloroform extraction of DNA from blood and tissues. Trends Genet. 5: 391.

22. Rouleau, G. A., Haines, J. L., Bazanowski, A., ColellaCrowley, A., Trofatter, J. A., Wexler, N. S., CoNNEALLY, P. M., AND GuSELLA, J. F. (1989). A genetic linkage map of the long arm of human chromosome 22. Genomics 4: 1-6.

23. Schwartz, D. C., AND CANTOR, C. R. (1984). Separation of yeast chromosome-sized DNAs by pulsed field gradient gel electrophoresis. Cell 37: 67-75.

24. White, R. L., Woodward, S., Leppert, M., O'ConNell, P., Hoff, M., Herbst, J., LaLouel, J. M., Dean, M., and Van DE WoUDE, G. (1985). A closely linked genetic marker for cystic fibrosis. Nature 318: 382-384. 